
\title{
28 Research Suare \\ Using 18F-FDG PET/CT to Predict Esophageal Cancer Survival: A Meta-analysis
}

\section{Jingying Wang}

Shanxi Medical University https://orcid.org/0000-0003-4128-8672

Jianbo Song

Shanxi Bethune Hospital

Sijin Li (D lisjnm123@163.com )

First Hospital of Shanxi Medical University, Taiyuan, Shanxi, China.

\section{Research}

Keywords: positron emission tomography, esophageal neoplasms, chemoradiotherapy

Posted Date: December 8th, 2020

DOI: https://doi.org/10.21203/rs.3.rs-120613/v1

License: (1) This work is licensed under a Creative Commons Attribution 4.0 International License. Read Full License 
1 Using 18F-FDG PET/CT to Predict Esophageal Cancer Survival: A Meta-

2 analysis

3 Type of manuscript: Research

4 Authors:

5 JingYing Wang, MSC

6 Department of Nuclear Medicine, First Hospital of Shanxi Medical University,

7 Taiyuan, China.

8 JianBo Song, MD.PhD

9 Department of Cancer Center, Shanxi Bethune Hospital, Taiyuan, China.

10 SiJin Li, MD. PhD.

11 Department of Nuclear Medicine, First Hospital of Shanxi Medical University,

12 Taiyuan, China.

13 Corresponding Author:

14 SiJin Li

15 Address: 85 Jiefang South Road, First Hospital of Shanxi Medical University,

16 Taiyuan, Shanxi, China.

17 Fax:0351-4048123

$18 \quad$ Tel:+8613934519222 


\section{Abstract}

23 Background: This study aimed to explore whether metabolic responses to

24 positron emission tomography/computed tomography (PET/CT) collected

25 before, during, or after the treatment can predict the long-term survival rate of

26 patients with esophageal cancer.

27 Main body: We searched for the following indices in articles listed in English

28 and Chinese literature databases: the maximum standard uptake value

29 (SUV $\max )$, mean standard uptake value (SUV $\left.V_{\text {mean }}\right)$, metabolic tumor volume

30 (MTV), and total lesion glycolysis (TLG). If their values exceeded the

31 thresholds, we defined them as responders; if they did not, we defined them as

32 non-responders. We then performed a meta-analysis by extracting the hazard

33 ratio $(\mathrm{HR})$ and $95 \%$ confidence interval $(95 \% \mathrm{Cl})$ from each report to predict

34 whether the status of responder or non-responder had an impact on prognosis.

35 We identified 34 articles with a combined sample size of 2794 patients. HRs

36 and $95 \%$ Cls were measured as follows: $\mathrm{SUV}_{\max }=1.15(0.98-1.35), \mathrm{MTV}=$

$373.45(0.78-15.25), T L G=1.04(1.02-1.07)$, and $S U V_{\text {mean }}=1.85(1.33-2.57)$

38 (before treatment); $\Delta S U V_{\max }=1.22(1.06-1.39), \Delta M T V=1.07(0.54-2.15)$, and 
$39 \Delta \mathrm{TLG}=1.09(0.59-2.02)$ (during treatment); and $S \mathrm{SV}_{\max }=1.13(1.05-1.22)$

40 and TLG $=1.05$ (1.02-1.09) (after treatment). The results showed that the

41 overall survival of the patients with low SUV (MTV, TLG) values was

42 significantly higher than that of the patients with high SUV (MTV, TLG) values.

43 Conclusions: This meta-analysis shows that the prognoses of patients with

44 PET metabolic responses are significantly better than those of non-responders.

45 Our findings may help inform the clinical treatment and prediction of the

46 prognoses of patients with esophageal cancer.

47 Keywords: positron emission tomography; esophageal neoplasms;

48 chemoradiotherapy

49

\section{Introduction}

51 Likely due to differences in economic development and living habits, the

52 incidence of upper gastrointestinal cancer is high in economically

53 underdeveloped areas, especially in East Asia and East Africa; for example,

54 the annual incidence of upper gastrointestinal cancer in China accounts for

$5544.6 \%$ of the global incidence of the disease [1]. Esophageal cancer is one of

56 the most common tumors of the upper digestive system. It is principally treated

57 with a combination of surgery and neoadjuvant or traditional radiotherapy and

58 chemotherapy. While this multimodal treatment has greatly reduced the 
59 mortality and improved the disease-free survival rate of patients with

60 esophageal cancer, the accurate prediction of the prognoses of patients

61 following the treatment has remained a challenge. A superb supplement to

62 traditional medical imaging, positron emission tomography (PET) has partially

63 replaced invasive examinations such as endoscopic biopsy as a method of

64 delineating the target area in the early stages of tumor radiotherapy and thus

65 holds a potential for improving the prediction of a patient's response to

66 radiotherapy, chemotherapy, and even surgery.

67 In the past, CT was typically used to stage esophageal cancer. However,

68 CT scans were not as useful 40 years ago as they are now. Despite its

69 regional limitation, endoscopic ultrasound has become the best staging

70 method. New tools are still needed to predict the prognosis of esophageal

71 cancer [2]. ${ }^{18} \mathrm{~F}$-fluorodeoxyglucose (FDG) PET has recently gained popularity

72 as a metabolic imaging modality. Many researchers have used it to evaluate

73 the efficacy or to predict the outcomes of radiotherapy, chemotherapy, and

74 surgery; FDG PET can thus help avoid the prescription of ineffective or

75 unnecessary treatments. We identified responders as patients with higher

76 standard uptake value (SUV) values before treatment and lower SUV values

77 after treatment, as well as patients with greater differences in SUV values

78 before and after treatment. The values of PET parameters used as response 
79 thresholds differ greatly, and most are based on experience; due to these

80 differences between articles, we have not listed the thresholds here.

81 As the literature featured no standardized guidelines, what changes in

82 PET parameters across treatment are considered to indicate prognosis vary.

83 Further, whether PET can predict the mortality and disease-free survival rate of

84 patients remains controversial. To help inform the resolution of this controversy

85 and contribute to a reference for clinical practice, the present meta-analysis of

86 all relevant and available literature aimed to conduct a systematic, objective

87 analysis of PET factors predictive of survival following esophageal cancer.

\section{Methods}

89 Literature search

90 We searched the Cochrane library MEDLINE, EMBASE, and China

91 National Knowledge Internet for documents published in Chinese or English

92 from any year. The following search query was used: "esophageal cancer" OR

93 "carcinoma of esophagus" OR "esophageal carcinoma" OR "esophagus

94 cancer" AND "positron emission tomography" OR "PET" AND "18F-FDG" OR

95 "fluorodeoxyglucose" AND "prognosis" OR "outcome" OR "prognostic" OR

96 "existence" OR "survival" OR "predict" (Fig 1).

97 Selection of studies 
$98 \quad$ The selected articles were independently evaluated by four researchers

99 (three clinical doctors and one professor of statistics) who did not communicate

100 with one another. Scores were tallied out of 36 points. Clear mention of indices

101 in the article earned 2 points, unclear mention of indices earned 1 point, and no

102 mention of indices earned 0 points (or based on the explanation in the

103 comments). The average of the four scores awarded by the researchers was

104 used as the final score. Disagreements were settled through discussion (Table

105 1). Further details regarding the method used to score each article are

106 described in the Appendix.

Table1. standard for evaluation

\begin{tabular}{|c|c|c|}
\hline Project & Specific meaning & Comments \\
\hline 1 & Clearly define the research object & \\
\hline \multirow[t]{2}{*}{2} & Study types & Prospective (2) \\
\hline & & Retrospective(1) \\
\hline \multirow[t]{2}{*}{3} & Clearly define the outcome of the event & $\begin{array}{l}\text { The optimal number of } \\
\text { samples (2) }\end{array}$ \\
\hline & & $\begin{array}{l}\text { Define the number of } \\
\text { samples (1) }\end{array}$ \\
\hline 4 & Application of statistical methods & \\
\hline 5 & Description of Statistical method & \\
\hline 6 & Criteria of patient included & \\
\hline 7 & Characteristics of patient included & \\
\hline 8 & Medical regulation and nursing convention & \\
\hline 9 & Description of treatment & \\
\hline
\end{tabular}


Including description of endings

12 There is direct HR and $95 \%$

Univariate survival analysis of prognostic CI (2) factors

There is no direct HR or $95 \%$ CI (1)

There is no way we can calculate HR (0)

13 Multivariate survival analysis of prognostic factors

There is direct HR and 95\%

CI (2)

There is no direct HR or $95 \%$ CI (1)

There is no way we can calculate HR (0)

14

PET report: Basic Information

15

${ }^{18}$ FDG-PET data acquisition

16

${ }^{18}$ FDG-PET technical parameters

17

Using the double-blind method

18

Clearly defined threshold

$\mathrm{HR}$, hazard ratio; $\mathrm{CI}$, confidence interval

\section{Statistical methods}


111 This paper selected four indices in each report to distinguish whether

112 responding depends on each author's experience or practical results: the

113 maximum standard uptake value (SUV $\max$ ), mean standard uptake value

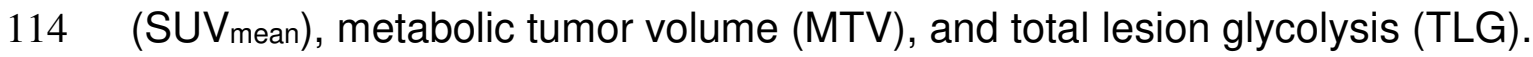

115 When merging statistical results, it was necessary to perform a heterogeneity

116 test to judge whether the statistics were heterogeneous. P-values of $\leq 0.100$

117 were considered to indicate heterogenous statistical results.

118 In Revman software, $\mathrm{I}^{2}$ can be used to describe the percentage of

119 heterogeneity caused by various studies rather than sampling errors in the total

120 heterogeneity. The formula used to calculate $\mathrm{I}^{2}$ is as follows:

$$
I^{2}=[Q-(k-1)] / Q \times 100 \%
$$

122 where $\mathrm{Q}$ represents the chi-square value $\left(\mathrm{X}^{2}\right)$ of the heterogeneity test, and $\mathrm{k}$

123 represents the number of included studies. $I^{2}$ values of $\leq 50 \%$ were considered

124 to indicate statistical significance. The values of the four indicators of the

125 survival rate selected in these papers were generated by the comparison of the

126 overall survival (OS) rate, as calculated from the hazards ratio (HR) and 95\%

127 confidence interval $(\mathrm{Cl})$, between the two groups. The HR was calculated with

128 the following formula:

129 pooled $\operatorname{lnHR}=\left[\frac{\sum \text { logrank Observed - Expected events }(\mathrm{O}-\mathrm{E})}{\sum \log \text { rankVariance }(V)}\right]$ 
130 pooled $\ln H R=\left[\frac{\sum \frac{\ln H R}{\text { Variance of the } \ln H R}}{\sum \frac{1}{\text { Variance of the } \ln H R}}\right]$

131 If $\mathrm{HR}$ and variance $(\mathrm{V})$ were mentioned in the original text, they could be

132 directly applied to the meta-analysis. The method of Jayne et al. [4] can be

133 used to calculate the $\mathrm{HR}$ and $95 \% \mathrm{Cl}$ in any case from the $\mathrm{K}-\mathrm{M}$ curve and $\mathrm{P}$ -

134 value. First, the approximate value of each point on the curve is obtained by

135 using Engauge Digitizer, and the approximate value of HR is calculated from

136 the Excel table accompanying the manuscript published by Jayne et al.

137 Revman is then used to calculate the upper and lower intervals of the $95 \% \mathrm{Cl}$.

138 If there are no censored data, the following formula can be used:

$139 \mathrm{HR}=\left[\frac{\text { Observed events research / log rank Expected events reseach }}{\text { Observed events control / log rank Expected events control }}\right]$

140 The survival rate of patients with low SUV values (low MTV values/TLG

141 values or high absolute value of $\Delta S U V$ ) is generally higher than that of patients

142 with high SUV values when $\mathrm{HR}>1.0$. By contrast, the survival rate of patients

143 with high SUV values (high MTV value/TLG value or low absolute value of

$144 \Delta S U V)$ is higher than that of patients with low SUV values when HR $\leq 1.0$.

145 If the results featured bias, we considered the subgroups analysis to

146 confirm the presence of publication bias. 
147 All the data were analyzed with Revman5.0 (The Nordic Cochrane Centre,

148 Copenhagen, Denmark), MetaXL5.3 (EpiGear International Pty Ltd,

149 Queensland, Australia), and Stata15.1 (StataCorp, Lakeway Drive, College

150 Station, Texas, USA).

151 Results

152 Study selection and characteristics analysis

153 Hundreds of articles were retrieved from the aforementioned databases.

154 After reading the titles and abstracts, 105 related articles were selected for

155 analysis. Articles were subsequently removed on account of the following: 1)

156 contents were unrelated to the target results, 2) extracting the $\mathrm{HR}$ and $95 \% \mathrm{Cl}$

157 was impossible, 3) the article was published more than once by the same

158 author, or 4) the study used other treatments or monitoring methods that

159 interfered with the extraction of the target results. Finally, 34 articles remained.

160 Articles containing only some of the target results and those featuring all of the

161 target information were extracted separately. Of these 34 articles, 24

162 considered the effect of SUV $\max$ before treatment[5-28]; nine, MTV before

163 treatment[16, 20, 22, 24-26, 28-31] ; seven, TLG before treatment[20, 21, 25,

$16426,28,29,31]$; three, $\mathrm{SUV}_{\text {mean }}$ on OS before treatment[21, 22, 25]; four,

$165 \mathrm{SUV}_{\max }$ after treatment[7, 13, 17, 26, 28, 32]; three, TLG after treatment[26, 28,

166 32]; 10, the effect of $\Delta S U V_{\max }$ before and after treatment[13, 17, 23, 26, 28, 33- 
167 37]; four, $\triangle M T V$ before and after treatment[26, 28, 36, 38]; and five, effect of

$168 \Delta$ TLG before and after treatment (Tables 2 and 3)[22, 26, 28, 36, 38].

Table1. standard for evaluation

\begin{tabular}{|c|c|c|}
\hline Project & Specific meaning & Comments \\
\hline 1 & Clearly define the research object & \\
\hline \multirow[t]{2}{*}{2} & Study types & Prospective (2) \\
\hline & & Retrospective(1) \\
\hline \multirow[t]{2}{*}{3} & Clearly define the outcome of the event & $\begin{array}{l}\text { The optimal number of } \\
\text { samples (2) }\end{array}$ \\
\hline & & $\begin{array}{l}\text { Define the number of } \\
\text { samples (1) }\end{array}$ \\
\hline 4 & Application of statistical methods & \\
\hline 5 & Description of Statistical method & \\
\hline 6 & Criteria of patient included & \\
\hline 7 & Characteristics of patient included & \\
\hline 8 & Medical regulation and nursing convention & \\
\hline 9 & Description of treatment & \\
\hline 10 & Number and reasons of excluded patients & \\
\hline 11 & $\underline{\text { follow-up period }}$ & $\begin{array}{l}\text { Including description of } \\
\text { endings }\end{array}$ \\
\hline \multirow[t]{5}{*}{12} & & There is direct HR and $95 \%$ \\
\hline & Univariate survival analysis of prognostic & CI (2) \\
\hline & factors & There is no direct HR or $95 \%$ \\
\hline & & CI (1) \\
\hline & & $\begin{array}{l}\text { There is no way we can } \\
\text { calculate HR (0) }\end{array}$ \\
\hline
\end{tabular}


There is no direct HR or $95 \%$

CI (1)

There is no way we can calculate HR (0)

$\begin{array}{ll}14 & \text { PET report: Basic Information } \\ 15 & { }^{18} \text { FDG-PET data acquisition } \\ 16 & { }^{18} \text { FDG-PET technical parameters } \\ 17 & \text { Using the double-blind method } \\ 18 & \text { Clearly defined threshold }\end{array}$

HR, hazard ratio; CI, confidence interval

\section{Quality assessment}

174 The lowest quality score of the 34 selected articles was 39 , and the

175 highest was 84 . The scoring system adopted by the reviewers was relatively

176 strict, and the document quality was relatively high. If an article lacked

177 necessary information, the corresponding author of the article was contacted.

178 Meta-analysis

179 A meta-analysis of the four indicators (SUV max $_{\text {, SUV }}$ SUn, MTV, and TLG)

180 before treatment was performed for OS. Twenty-four articles included the 
181 SUV $_{\max }$. Because the $\mathrm{I}^{2}=82 \%>50 \%$, these articles were analyzed with the

182 QE model $(\mathrm{HR}=1.15,95 \% \mathrm{Cl}=0.98-1.35)$. The results showed that the $\mathrm{OS}$ of

183 the patients with low SUV $\max$ was significantly higher than that of the patients

184 with a high SUV $\max ($ Fig. 2A, 2B, 2C).

185 The asymmetry of the funnel chart suggested publication bias. The two

186 methods of Begg and Egger of Stata used to detect the publication bias

187 indicated contradictory results. For a small sample, the Egger method (Fig. 3A)

188 is more sensitive than the Begg (Fig. 3B) method. The result of $P=0.000$

189 indicated that the selected articles were subject to publication bias.

190 Because of the large heterogeneity, we performed subgroup analyses. The 191 patients were categorized according to the following pathological types (articles

192 that did not mention pathological types were excluded): squamous cell

193 carcinoma, adenocarcinoma, and unsegmented. The HR and $95 \% \mathrm{Cl}$ of each

194 subgroup were 3.69 (1.68-8.09), $0.96(0.89-1.04)$, and $1.41(1.16-1.71)$,

195 respectively. These values were significantly different $(p<0.00001)$.

196 The patients were further categorized according to the pathological stage

197 of their cancer (articles that did not mention the stage were excluded): stage III

198 or earlier, and stage IV or earlier. The $\mathrm{HR}$ and $95 \% \mathrm{Cl}$ of each subgroup were

1992.35 (1.59-3.48) and $1.52(1.17-1.97)$, respectively. There was no significant

200 difference between the two groups $(p=0.07)$. 
202 chemotherapy (S), operation (O), and undifferentiated treatment $(\mathrm{N})$. The HR

203 and $95 \% \mathrm{Cl}$ of each subgroup were 1.63 (1.32-2.02), 2.07 (1.20-3.55), and

$2041.19(0.95-1.49)$, respectively. No significant difference was found between the 205 three groups $(P=0.06$, Fig. 4A, 4B, 4C).

206 Nine articles included in our analysis considered MTV. Because the $\mathrm{I}^{2}=$ $207100 \%>50 \%$, these articles were analyzed with the QE model ( $\mathrm{HR}=3.45,95 \%$

$208 \mathrm{Cl}=0.78-15.25)$. Our results showed that the OS of the patients with low MTV

209 values was significantly higher than that of the patients with high MTV values.

210 Seven articles included in our analysis considered TLG. Because the $\mathrm{I}^{2}=$ $21181 \%>50 \%$, these articles were analyzed with the QE model $(\mathrm{HR}=1.04,95 \%$

$212 \mathrm{Cl}=1.02-1.07)$. The results showed that the OS of the patients with low TLG

213 values was significantly higher than that of the patients with high TLG values.

214 Three articles included in our analysis considered the SUVmean. Because

215 the $\mathrm{I}^{2}=48 \%<50 \%$, these articles were analyzed with the fixed-effect model

$216(\mathrm{HR}=1.85,95 \% \mathrm{Cl}=1.33-2.57)$. The results showed that the OS of the

217 patients with low SUV mean scores was significantly higher than that of the

218 patients with high SUV $V_{\text {mean }}$ scores.

219 Meta-analysis of the three indicators ( $\triangle \mathrm{SUV}_{\max }, \Delta \mathrm{MTV}$, and $\left.\Delta T L G\right)$

220 measured during treatment was performed. Ten articles included in our 
221 analysis considered the $\Delta S U V_{\max }$. Because the $\mathrm{I}^{2}=48 \%<50 \%$, these articles

222 were analyzed with the fixed-effect model $(\mathrm{HR}=1.22,95 \% \mathrm{Cl}=1.06-1.39)$. The

223 results showed that the OS of the patients with high absolute values of

$224 \Delta S U V_{\max }$ was significantly higher than that of the patients with low absolute

225 values of $\Delta S U V_{\max }$

226 Four articles included in our analysis considered the $\Delta$ MTV. Because the

$227 \mathrm{I}^{2}=90 \%>50 \%$, these articles were analyzed with the QE model $(\mathrm{HR}=1.07$,

$22895 \% \mathrm{Cl}=0.54-2.15)$. The results showed that the OS of patients with high

229 absolute values of $\triangle M T V$ was significantly higher than that of the patients with

230 low absolute values of $\triangle M T V$.

$231 \quad$ Five articles included in our analysis considered the $\Delta$ TLG. Because the $\mathrm{I}^{2}$

$232=87 \%>50 \%$, these articles were analyzed with the QE model $(H R=1.09,95 \%$

$233 \mathrm{Cl}=0.59-2.02)$. The results showed that the OS of the patients with high

234 absolute values of $\Delta$ TLG was significantly higher than that of the patients with

235 low absolute values of $\Delta T L G$.

236 Meta-analysis of the two indicators (SUV $\max$ and TLG) measured after

237 treatment was performed. Six articles included in our analysis considered the

238 SUV $\max$. Because the $\mathrm{I}^{2}=58 \%>50 \%$, these articles were analyzed with the

239 QE model $(\mathrm{HR}=1.13,95 \% \mathrm{Cl}=1.05-1.22)$. The results showed that the $\mathrm{OS}$ of 
240 the patients with low SUV $\max$ values was significantly higher than that of the

241 patients with high SUV $\max$ values.

242 Three articles included in our analysis considered TLG. Because the $\mathrm{I}^{2}=$

$24391 \%>50 \%$, these articles were analyzed with the QE model $(H R=1.05,95 \%$

$244 \mathrm{Cl}=1.02-1.09)$. The results showed that the OS of the patients with low TLG

245 values was significantly higher than that of the patients with high TLG values.

\section{Discussion}

247 The sixth leading cause of cancer-related death and the eighth most

248 common cancer in the world, esophageal cancer is associated with a 5-year

249 survival rate of less than $25 \%$ [39]. While endoscopy, CT, and MRI have

250 conventionally been used to examine patients with esophageal cancer, the

251 relatively new technique of PET has been increasingly used for the diagnosis,

252 differential diagnosis, and clinical staging of patients with esophageal cancer.

253 Imaging also helps to identify patients with significant complications who may

254 respond to and benefit from more conservative treatment (i.e., without

255 esophagectomy) after CRT is demonstrated to be fully or partially effective.

256 Finally, PET/CT has demonstrated value as a follow-up tool for the timely

257 detection of tumor recurrence after surgical treatment [40]. However, because

$258{ }^{18} \mathrm{~F}-\mathrm{FDGPET}$ can help to inform the metabolic diagnosis of esophageal cancer,

259 it can compensate for the shortcomings of traditional methods and predict the 
260 prognosis of patients when combined with CT to construct a clear anatomical

261 image. A study found ${ }^{18} \mathrm{~F}$-FDG PET/CT to be a powerful prognostic tool for

262 evaluating OS in patients with esophageal cancer before, during, or after

263 chemoradiation (CTRT). PET parameters $(T L G=50)$ can guide future

264 treatment strategies by stratifying stage II/III patients who will receive CTRT

265 according to their predicted OS [41]. Another study showed that PET could

266 reflect the response of esophageal cancer to neoadjuvant chemotherapy: the

267 SUV values of the PET responders were significantly higher than those of the

268 PET non-responders [42]. However, SUV changes and PET responses were

269 not found by the study to be associated with prognosis.

270 The articles selected in this meta-analysis featured considerable

271 heterogeneity. The use of the traditional RE model and the square of tau $\left(\mathrm{T}^{2}\right)$ to

272 measure the differences between studies indicated large variance in the results

273 of small samples, which leads to small weights. When calculating the weights

274 in each study, the same $\mathrm{T}^{2}$ values are used for the denominators; hence, small

275 studies will contribute a disproportionately large weight, while the weight of

276 large studies will be reduced. The QE model is used to resolve the drawback of

277 the RE model.

278 For cases with large heterogeneity, subgroup analysis was used to identify

279 the source of heterogeneity. For studies providing the SUV $V_{\max }$ before

280 treatment, the possible causes of heterogeneity include, sex, age, treatment 
281 plan, clinical stage, pathological type, sample size, and article quality scores.

282 However, as most articles did not make a clear distinction between sex and

283 age, the present meta-analysis considered the patient's treatment plan, clinical

284 stage, and pathological type as sources of heterogeneity.

285 When the patients were divided according to pathological type, the value

286 of SUV $\max$ could predict the OS of patients with squamous cell carcinoma and

287 undifferentiated pathologies but not for those with adenocarcinoma

288 pathologies. The difference between the three groups was statistically

289 significant, indicating that the relationships between pathological type, the

290 value of SUV $\max$, and OS are unclear and that the ${ }^{18} \mathrm{~F}-\mathrm{FDG}$ uptake of

291 adenocarcinoma cells is not as effective as that of squamous cells (low or no

292 uptake can be seen in $10 \%$ to $15 \%$ of undifferentiated adenocarcinomas).

293 Hence, caution should be exercised when using the SUV max to predict the OS

294 of patients whose esophageal cancer follows the pathological pattern of

295 adenocarcinomas.

296 When subgroups were divided according to stage, we found no significant

297 difference between patients with cancer before or at stage III and those with

298 cancer before or at stage IV. However, it is possible that SUV $\max$ is more

299 effective as a predictor of esophageal cancer in the early and middle stages of

300 cancer because the group of patients with cancer before or at stage IV 
301 includes patients with cancer before or at stage III. More experiments are 302 needed to confirm this hypothesis.

303 When the patients were sorted according to treatment, we found no

304 significant difference between the four groups. While the methods of

305 radiotherapy and chemotherapy, drug use, radiation dose, target delineation,

306 and even surgical methods differed among the reviewed studies, the analyses

307 of each subgroup confirmed that SUV $\max$ could still be used to predict OS.

308 The overall analysis revealed that regardless of whether the indices were

309 measured before or after treatment, SUV $\max$, MTV, TLG, and SUV mean could

310 perform well in predicting the OS of patients; the value of MTV is related to the

311 size of the solid tumor, while the values of SUV $\max$ and TLG are related to the

312 pathological response. Hence, SUV $\max$ and TLG can directly predict the

313 efficacy of radiotherapy, chemotherapy, and surgery.

314 This report is subject to several limitations. First, many of the included

315 articles did not directly report HR values but instead extracted them through

316 the K-M curve. This method inevitably results in mistakes. Second, the funnel

317 chart of the reports collected from the literature was subject to publication bias,

318 likely resulting in the overestimation of the presently identified predictive effect

319 of the indices. Finally, all of the reports sourced from the literature are case-

320 control or cohort studies, highlighting the need for large randomized controlled 
321 trials of the potential of PET/CT for predicting the prognoses of patients with

322 esophageal cancer.

\section{Conclusion}

324 Although our study is subject to limitations, it demonstrates that the

325 prognoses of patients who respond to PET are significantly better than those of

326 non-responders. Hence, our study can help to inform the prediction of the

327 prognoses of patients with esophageal cancer and, therefore, their treatment.

329 List of abbreviations

$330 \quad{ }^{18} \mathrm{~F}$-fluorodeoxyglucose: FDG

$33195 \%$ confidence interval: $95 \% \mathrm{Cl}$

332 Chemoradiation: CTRT

333 Hazard ratio: HR

334 Maximum standard uptake value: SUVmax

335 Mean standard uptake value: SUVmean

336 Metabolic tumor volume: MTV

337 Overall survival: OS

338 Positron emission tomography/computed tomography: PET/CT 
339 Total lesion glycolysis: TLG

\section{Declarations}

341 Ethics approval and consent to participate : Not applicable

342 Consent for publication : Not applicable

343 Availability of data and materials : The datasets used and/or analyzed during

344 the current study are available from the corresponding author upon reasonable

345 request.

346 Competing interests : The authors declare that they have no competing

347 interests.

348 Funding : There was no funding for this study.

349 Authors' contributions: JW conducted data curation, performed formal analysis,

350 and wrote this paper. JS managed conceptualization and project

351 administration. SL constructed the methodology, and reviewed and edited the

352 paper.

353 Acknowledgements : Not applicable

354 Authors' information (optional)

\section{REFERENCES}

356 1. Arnold M, Abnet CC, Neale RE, Vignat J, Giovannucci EL, McGlynn KA, et al. Global Burden of 5 Major

357 Types Of Gastrointestinal Cancer. Gastroenterology. 2020. 
358 2. Faigel DO. The Role of Endoscopic Ultrasound in Esophageal Cancer. Gastroenterol Hepatol (N Y).

$359 \quad 2019 ; 15: 519-21$.

360 3. Mantziari S, Pomoni A, Prior JO, Winiker M, Allemann P, Demartines N, et al. 18F- FDG PET/CT-derived parameters predict clinical stage and prognosis of esophageal cancer. BMC Med Imaging. 2020;20:7.

362 4. Tierney JF, Stewart LA, Ghersi D, Burdett S, Sydes MR. Practical methods for incorporating summary timeto-event data into meta-analysis. Trials. 2007;8:16.

364 5. Fukunaga T, Okazumi S, Koide Y, Isono K, Imazeki K. Evaluation of esophageal cancers using fluorine-18365 fluorodeoxyglucose PET. J Nucl Med. 1998;39:1002-7.

366 6. Kato H, Kuwano H, Nakajima M, Miyazaki T, Yoshikawa M, Ojima H, et al. Comparison between positron emission tomography and computed tomography in the use of the assessment of esophageal carcinoma. Cancer. 2002;94:921-8.

7. Swisher SG, Erasmus J, Maish M, Correa AM, Macapinlac H, Ajani JA, et al. 2-Fluoro-2-deoxy-D-glucose

8. van Westreenen HL, Plukker JT, Cobben DC, Verhoogt CJ, Groen H, Jager PL. Prognostic value of the positron emission tomography imaging is predictive of pathologic response and survival after preoperative standardized uptake value in esophageal cancer. AJR Am J Roentgenol. 2005;185:436-40. esophageal cancer predicts stage, tumor biology, and survival. Ann Thorac Surg. 2006;82:391-4; discussion $394-5$.

10. Rizk N, Downey RJ, Akhurst T, Gonen M, Bains MS, Larson S, et al. Preoperative 18[F]fluorodeoxyglucose positron emission tomography standardized uptake values predict survival after esophageal adenocarcinoma resection. Ann Thorac Surg. 2006;81:1076-81.

11. Cheze-Le Rest C, Metges JP, Teyton P, Jestin-Le Tallec V, Lozac'h P, Volant A, et al. Prognostic value of initial fluorodeoxyglucose-PET in esophageal cancer: a prospective study. Nucl Med Commun. 2008;29:628-35.

12. Chung HW, Lee KH, Lee EJ, Lee SJ, Cho YS, Choi JY, et al. Comparison of uptake characteristics and prognostic value of 201Tl and 18F-FDG in esophageal cancer. World J Surg. 2008;32:69-75.

13. Javeri H, Xiao L, Rohren E, Komaki R, Hofstetter W, Lee JH, et al. Influence of the baseline 18F-fluoro-2deoxy-D-glucose positron emission tomography results on survival and pathologic response in patients with gastroesophageal cancer undergoing chemoradiation. Cancer. 2009;115:624-30.

14. Javeri H, Xiao L, Rohren E, Lee JH, Liao Z, Hofstetter W, et al. The higher the decrease in the standardized uptake value of positron emission tomography after chemoradiation, the better the survival of patients with gastroesophageal adenocarcinoma. Cancer. 2009;115:5184-92. 
15. Rizk NP, Tang L, Adusumilli PS, Bains MS, Akhurst TJ, Ilson D, et al. Predictive value of initial PETSUVmax in patients with locally advanced esophageal and gastroesophageal junction adenocarcinoma. $\mathrm{J}$ Thorac Oncol. 2009;4:875-9.

16. Zhu WQ, Yu JM, Sun XR, et al. The prognostic valHe of metabolic tumor volume in FDG PET / CT eva]uation of post —operative survival in patients with esophageal squamous cell cancer. Chin J Nucl Med.2011;31:378-81.

17. Kauppi JT, Oksala N, Salo JA, Helin H, Karhumäki L, Kemppainen J, et al. Locally advanced esophageal adenocarcinoma: response to neoadjuvant chemotherapy and survival predicted by ([18F])FDG-PET/CT. Acta Oncol. 2012;51:636-44.

18. Yanagawa M, Tatsumi M, Miyata H, Morii E, Tomiyama N, Watabe T, et al. Evaluation of response to neoadjuvant chemotherapy for esophageal cancer: PET response criteria in solid tumors versus response evaluation criteria in solid tumors. J Nucl Med. 2012;53:872-80.

19. Kajiwara T, Hiasa Y, Nishina T, Matsumoto T, Hori S, Nadano S, et al. Maximum standardized uptake value in $18 \mathrm{~F}$-fluoro-2-deoxyglucose positron emission tomography is associated with advanced tumor factors in esophageal cancer. Mol Clin Oncol. 2014;2:313-21.

20. Xie YT. Impact of F-FDG PET/CT before radiotherapy on treatment regimen and prognostic significance of PET/CT parameters in patients with esophageal cancer . Peking union medical college (department of medicine, tsinghua university) \& Chinese academy of medical sciences, trans. In: zheng rong, Ed. Imaging medicine and nuclear medicine. ,2014.

21. Bütof R, Hofheinz F, Zöphel K, Stadelmann T, Schmollack J, Jentsch C, et al. Prognostic Value of Pretherapeutic Tumor-to-Blood Standardized Uptake Ratio in Patients with Esophageal Carcinoma. J Nucl Med. 2015;56:1150-6.

22. Chang S, Kim SJ. Prediction of Recurrence and Mortality of Locally Advanced Esophageal Cancer Patients Using Pretreatment F-18 FDG PET/CT Parameters: Intratumoral Heterogeneity, SUV, and Volumetric Parameters. Cancer Biother Radiopharm. 2016;31:1-6.

23. Hamai Y, Hihara J, Emi M, Furukawa T, Yamakita I, Kurokawa T, et al. Ability of Fluorine-18 Fluorodeoxyglucose Positron Emission Tomography to Predict Outcomes of Neoadjuvant Chemoradiotherapy Followed by Surgical Treatment for Esophageal Squamous Cell Carcinoma. Ann Thorac Surg. 2016;102:1132-9.

24. Huang CH, Shi DH, Cui XX, Xiao XC, Cai J. The maximum standard value of FDG before treatment was used to predict the radiotherapy effect of local advanced esophageal cancer. Med J of Communications. 2016;30:175-178.

25. Nakajo M, Jinguji M, Nakabeppu Y, Nakajo M, Higashi R, Fukukura Y, et al. Texture analysis of 18F-FDG $\mathrm{PET} / \mathrm{CT}$ to predict tumour response and prognosis of patients with esophageal cancer treated by chemoradiotherapy. Eur J Nucl Med Mol Imaging. 2017;44:206-14. 
26. Bütof R, Hofheinz F, Zöphel K, Schmollack J, Jentsch C, Zschaeck S, et al. Prognostic value of SUR in patients with trimodality treatment of locally advanced esophageal carcinoma. J Nucl Med. 2018.

27. Dai L, Fu H, Wang F, Guo R, Yang YB, Lin Y, Lu KN. Analysis of relationship between18F-FDG PET/CT SUVmax of esophageal squamous cell carcinoma before treatment and postoperative survival. Natl Med J

28. Li Y, Zschaeck S, Lin Q, Chen S, Chen L, Wu H. Metabolic parameters of sequential 18F-FDG PET/CT predict overall survival of esophageal cancer patients treated with (chemo-) radiation. Radiat Oncol. 2019;14:35.

31. Hofheinz F, Li Y, Steffen IG, Lin Q, Lili C, Hua W, et al. Confirmation of the prognostic value of

32. Cervino AR, Pomerri F, Alfieri R, Sileni VC, Castoro C, Galuppo S, et al. 18F-fluorodeoxyglucose

33. Weber WA, Ott K, Becker K, Dittler HJ, Helmberger H, Avril NE, et al. Prediction of response to

34. Ott K, Weber WA, Lordick F, Becker K, Busch R, Herrmann K, et al. Metabolic imaging predicts response,

35. Lordick F, Ott K, Krause BJ, Weber WA, Becker K, Stein HJ, et al. PET to assess early metabolic response and to guide treatment of adenocarcinoma of the oesophagogastric junction: the MUNICON phase II trial.

36. Roedl JB, Colen RR, Holalkere NS, Fischman AJ, Choi NC, Blake MA. Adenocarcinomas of the esophagus: response to chemoradiotherapy is associated with decrease of metabolic tumor volume as measured on PETCT. Comparison to histopathologic and clinical response evaluation. Radiother Oncol. 2008;89:278-86. 
38. Kim SJ, Koo PJ, Chang S. Predictive value of repeated F-18 FDG PET/CT parameters changes during preoperative chemoradiotherapy to predict pathologic response and overall survival in locally advanced esophageal adenocarcinoma patients. Cancer Chemother Pharmacol. 2016;77:723-31.

39. Then EO, Lopez M, Saleem S, Gayam V, Sunkara T, Culliford A, et al. Esophageal Cancer: An Updated Surveillance Epidemiology and End Results Database Analysis. World J Oncol. 2020;11:55-64.

40. Goense L, van Rossum PS, Reitsma JB, Lam MG, Meijer GJ, van Vulpen M, et al. Diagnostic Performance of ${ }^{18} \mathrm{~F}-\mathrm{FDG}$ PET and PET/CT for the Detection of Recurrent Esophageal Cancer After Treatment with Curative Intent: A Systematic Review and Meta-Analysis. J Nucl Med. 2015;56:995-1002. positron emission computed tomography as predictive of response after chemoradiation in oesophageal cancer patients. Eur J Cancer. 2015;51:2545-52.

42. Weber MA, Bender K, von Gall CC, Stange A, Grünberg K, Ott K, et al. Assessment of diffusion-weighted MRI and 18F-fluoro-deoxyglucose PET/CT in monitoring early response to neoadjuvant chemotherapy in 
Table3. Indices from the studies in the meta-analysis

\begin{tabular}{|c|c|c|c|}
\hline Study & Index & Time & Threshold \\
\hline \multirow[t]{3}{*}{ Nakajo2016 } & SUVmax & Before & NM \\
\hline & SUVmin & Chemoradiotherapy & \\
\hline & MTV TLG & & \\
\hline \multirow[t]{3}{*}{ Butof 2015} & SUVmax & Before radiotherapy & SUVmax $>8.5$ SUVmean $>8.14$ \\
\hline & SUVmin & & MTV>8.5 TLG $>12.4$ \\
\hline & MTV TLG & & \\
\hline \multirow[t]{4}{*}{ Rebecca2018 } & SUV MTV & Before and after & Pre:SUV>13.4 MTV>26.3 TLG>121 \\
\hline & TLG & Chemoradiotherapy & Post:SUV>5.33 MTV>6.6 TLG>30.2 \\
\hline & & & $\Delta \mathrm{SUV}>38.8 \% \Delta \mathrm{MTV}>35 \%$ \\
\hline & & & $\Delta \mathrm{TLG}>38.8 \%$ \\
\hline \multirow[t]{2}{*}{ Hamai2016 } & SUVmax & Before and after & Post:SUVmax $>5.33 \Delta$ SUVmax $>75 \%$ \\
\hline & & Chemoradiotherapy & \\
\hline \multirow[t]{2}{*}{ Kauppi2012 } & SUV & Before and after & Pre:SUVNM Post:SUVNM \\
\hline & & Chemoradiotherapy & $\triangle \mathrm{SUV}>67 \%$ \\
\hline \multirow[t]{6}{*}{ Li2019 } & SUVmax & Before and after & Pre:SUVmax>9.6MTV>10.5TLG>59. \\
\hline & MTV TLG & radiotherapy & 8 \\
\hline & & & Post:SUVmax $>7.8$ MTV>15.9 \\
\hline & & & $\mathrm{TLG}>44.3$ \\
\hline & & & $\triangle \mathrm{SUVmax}>23 \% \Delta \mathrm{MTV}>7.5 \%$ \\
\hline & & & $\Delta \mathrm{TLG}>27 \%$ \\
\hline Huang2016 & SUVmax & Before radiotherapy & SUVmax $>9.7$ \\
\hline \multirow[t]{2}{*}{ Xie2014 } & SUVmax & Before radiotherapy & SUVmax $\geq 11.4$ \\
\hline & MTV TLG & & $\mathrm{MTV} \geq 8.27 \mathrm{TLG} \geq 35.21$ \\
\hline Risk2006 & SUVmax & before operation & SUVmax $>4.5$ \\
\hline \multirow[t]{2}{*}{ Chang2016 } & SUVmax & before & SUVmax $>4.86$ SUVmean $>2.37$ \\
\hline & SUVmean & Chemoradiotherapy & MTV>8.93 TLG $>20.42$ \\
\hline
\end{tabular}


MTV TLG

\begin{tabular}{|c|c|c|c|}
\hline Rest2008 & SUVmax & before operation & SUVmax $>9$ \\
\hline Dai2018 & SUVmax & Before treatment & SUVmax $>6$ \\
\hline Hiasa2014 & SUVmax & Before treatment & SUVmax $>10.26$ \\
\hline Toru1993 & SUV & before operation & SUV $\geq 7.0$ \\
\hline Cerfolio2006 & SUV & before operation & SUV $\geq 6.6$ \\
\hline Chung2007 & SUV & before operation & $\mathrm{SUV} \geq 15$ \\
\hline Kato2002 & SUV & before operation & SUV $\geq 3$ \\
\hline Lordick2007 & SUV & $\begin{array}{l}\text { Before and after } \\
\text { treatment }\end{array}$ & $\triangle \mathrm{SUV} \geq 35 \%$ \\
\hline Ott2006 & SUV & $\begin{array}{l}\text { Before and after } \\
\text { treatment }\end{array}$ & $\triangle \mathrm{SUV} \geq 35 \%$ \\
\hline Risk2009 & SUV & $\begin{array}{l}\text { Before } \\
\text { Chemotherapy }\end{array}$ & SUVmax $\geq 4.5$ \\
\hline
\end{tabular}

\section{Continued}

485

\begin{tabular}{|c|c|c|c|}
\hline Study & Index & Time & Threshold \\
\hline \multirow[t]{3}{*}{ Roed12008 } & SUVmax & Before and after & $\triangle \mathrm{SUVmax} \geq 43 \%$ \\
\hline & SUVmean & treatment & $\triangle$ SUVmean $\geq 22 \%$ \\
\hline & MTV TLG & & $\Delta \mathrm{MTV} \geq 63 \% \quad \Delta \mathrm{TLG} \geq 78 \%$ \\
\hline \multirow[t]{2}{*}{ Swisher2004 } & SUV & Before and after & Pre:SUV>9.5 \\
\hline & & Chemoradiotherapy & Post:SUV>4 \\
\hline Heta2009 & SUV & $\begin{array}{l}\text { Before and after } \\
\text { treatment }\end{array}$ & $\Delta \mathrm{SUV}>52 \%$ \\
\hline \multirow[t]{2}{*}{ Heta2008 } & SUV & Before & SUV $>10.1$ \\
\hline & & Chemoradiotherapy & \\
\hline $\begin{array}{l}\text { Vanwestreenen2 } \\
005\end{array}$ & SUVmax & Before treatment & SUVmax $\geq 6.7$ \\
\hline
\end{tabular}




\begin{tabular}{|c|c|c|c|}
\hline Weber 2001 & SUV & $\begin{array}{l}\text { Before and after } \\
\text { Chemotherapy }\end{array}$ & $\triangle \mathrm{SUV} \geq 35 \%$ \\
\hline Zhu2011 & $\begin{array}{l}\text { SUVmax } \\
\text { MTV }\end{array}$ & $\begin{array}{l}\text { before } \\
\text { operation }\end{array}$ & $\begin{array}{l}\text { SUVmax }>11.6 \\
\text { MTV }>14.5\end{array}$ \\
\hline Yu2018 & MTV & $\begin{array}{l}\text { before } \\
\text { operation }\end{array}$ & NM \\
\hline Lin2018 & MTV TLG & $\begin{array}{l}\text { before } \\
\text { operation }\end{array}$ & MTV $\geq 27.44 \quad$ TLG $\geq 166.2$ \\
\hline Hofheinz2019 & $\begin{array}{l}\text { SUV } \\
\text { MTV TLG }\end{array}$ & $\begin{array}{l}\text { Before } \\
\text { Chemoradiotherapy }\end{array}$ & $\begin{array}{l}\text { MTV }>22.3 \quad \text { TLG }>46 \\
\text { SUV NM }\end{array}$ \\
\hline Huang2015 & SUV & $\begin{array}{l}\text { Before and after } \\
\text { Chemoradiotherapy }\end{array}$ & $\Delta \mathrm{SUV}>60 \%$ \\
\hline Kim2016 & $\begin{array}{l}\text { SUVmax } \\
\text { MTV TLG }\end{array}$ & $\begin{array}{l}\text { Before and after } \\
\text { radiotherapy }\end{array}$ & $\begin{array}{l}\Delta \mathrm{SUVmax}>23.5 \\
\Delta \mathrm{MTV}>25.5 \% \Delta \mathrm{TLG}>44.8 \%\end{array}$ \\
\hline Anna2014 & SUV & after radiotherapy & NM \\
\hline Yanagawa2012 & SUV & $\begin{array}{l}\text { Before and after } \\
\text { chemotherapy }\end{array}$ & NM \\
\hline
\end{tabular}

$\mathrm{NM}$, not mentioned; $\mathrm{SUV}_{\max }$, the maximum standard uptake value; $\mathrm{SUV}_{\text {mean }}$, mean standard uptake value; MTV, metabolic tumor volume; TLG, total lesion glycolysis; $\Delta$ means differences before and after treatment. 
$491 \quad$ Figure Legends

492 Figure 1 Flowchart of the selection of articles.

493 Figure 2 Forest plots of SUV max before treatment (A). Z-score of 24 studies

494 before treatment (B). Funnel Plots of SUV $\max$ before treatment. These articles

495 may be subject to publication bias (C). ES = effect size (hazard ratio), SUV $V_{\max }$

$496=$ the maximum standard uptake value.

497 Figure 3 Egger's test of SUV $V_{\max }$ before treatment $(A)$. Begg's test of SUV $\max$ 498 before treatment (B). SUV $\max =$ the maximum standard uptake value.

499 Figure 4 Forest plots of the SUV $\max$ subgroup according to pathological type 500 (A), stage of cancer (B), and type of treatments $(C) . S U V_{\max }=$ the maximum 501 standard uptake value. 


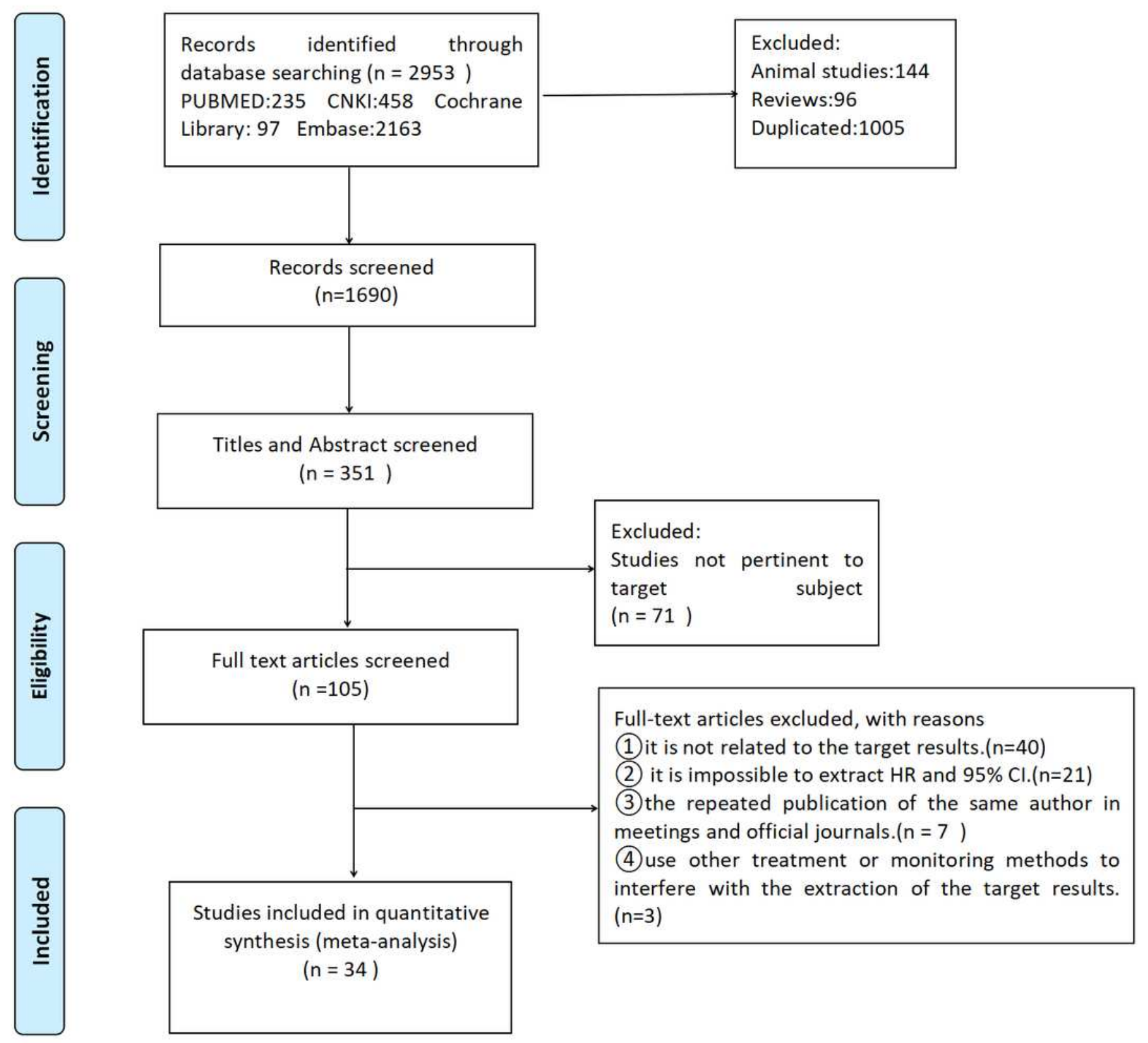

\section{Figure 1}

Flowchart of the selection of articles. 

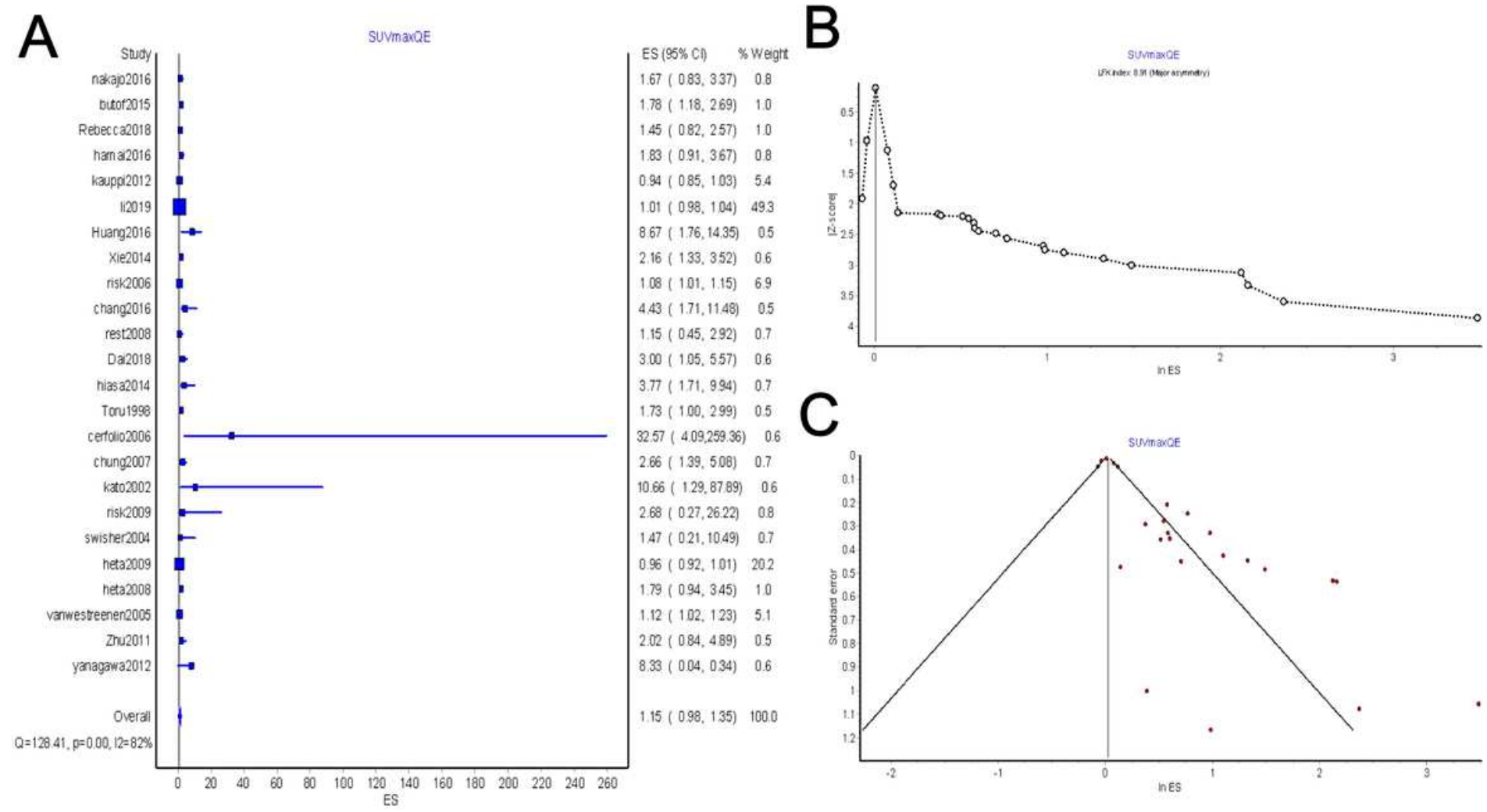

\section{Figure 2}

Forest plots of SUVmax before treatment (A). Z-score of 24 studies before treatment (B). Funnel Plots of SUVmax before treatment. These articles may be subject to publication bias (C). ES = effect size (hazard ratio), SUVmax = the maximum standard uptake value. 


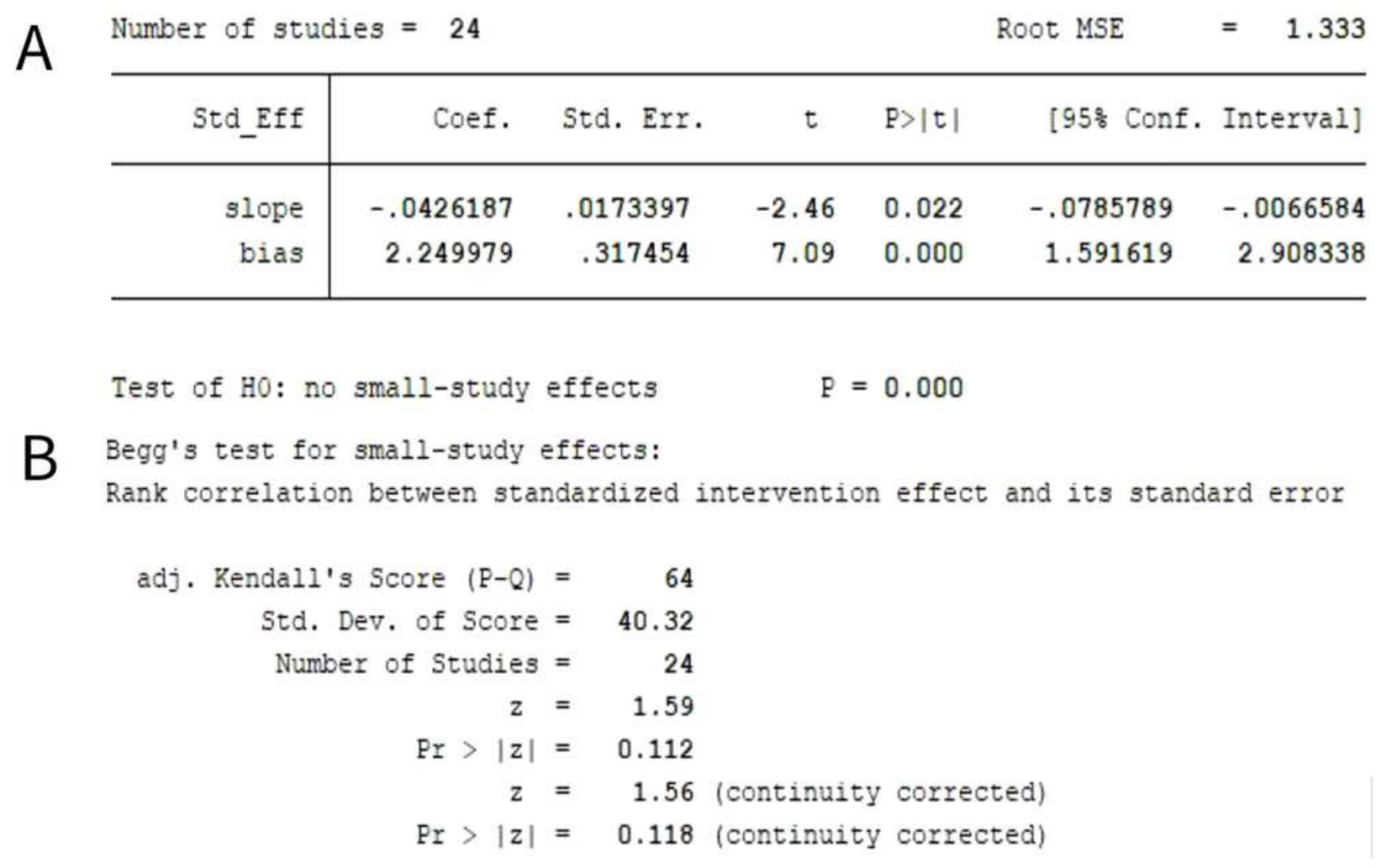

\section{Figure 3}

Egger's test of SUVmax before treatment (A). Begg's test of SUVmax before treatment (B). SUVmax = the maximum standard uptake value.

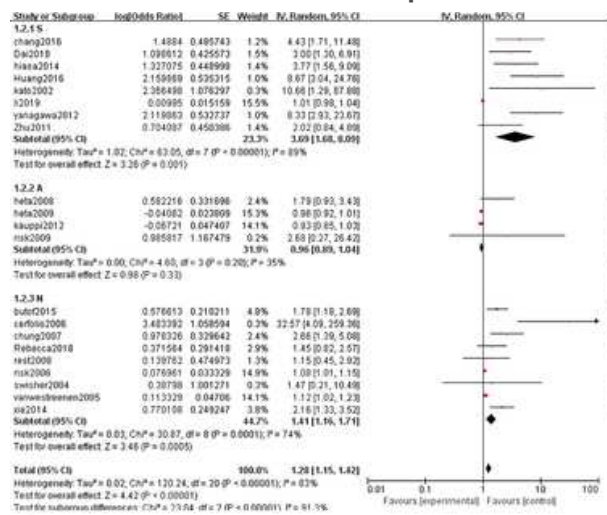

A

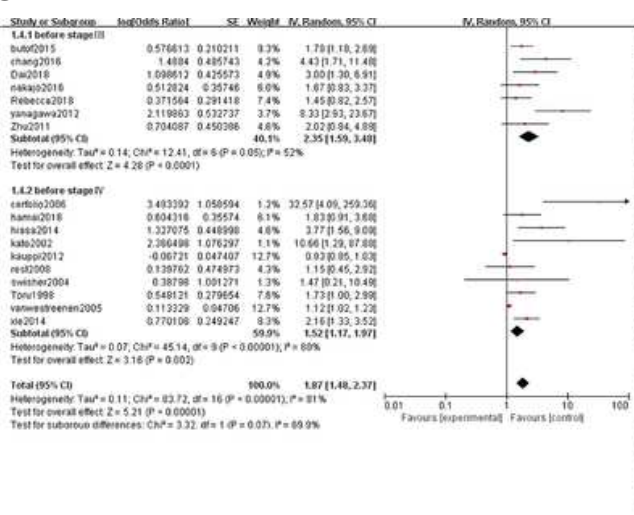

B

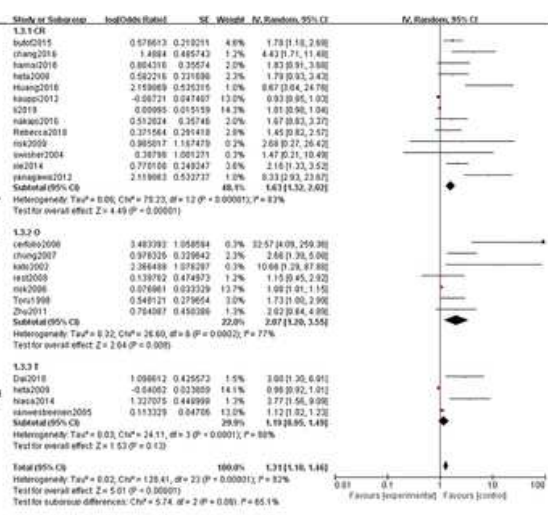

C

\section{Figure 4}

Forest plots of the SUVmax subgroup according to pathological type (A), stage of cancer (B), and type of treatments (C). SUVmax = the maximum standard uptake value. 